\title{
Development of Insulation Support Frame Used in Live Breaking and Joining Leads of $10 \mathrm{kV}$ Cable \\ $\mathrm{Li}$ Xu, Jie Niu, Yu Yan \& Jinliang Li \\ Live Working Centre of State Grid Corporation of Hunan, Changsha, China
}

Yanyi $\mathrm{Fu}$

State Grid Xiangxi Power Supply Company, Xiangxi, China

\begin{abstract}
In view of the security risks in live breaking and joining leads of $10 \mathrm{kV}$ cable, a kind of insulation support frame, which could fix cable leads effectively, was designed. Its mechanical strength was checked. Its mechanical behavior and electrical performance could meet the requirements of the regulations. At last, the operation procedure was introduced.
\end{abstract}

KEYWORD: cable; live working; support frame; structure design

\section{INTRODUCTION}

With the improvement of people's living standards, the expectation of distribution reliability and uninterrupted power supply of $10 \mathrm{kV}$ distribution network by users is becoming increasingly higher. It is difficult to control the time of form power maintenance to restore power supply. Reliability of power supply will decline (Hu Yi et al, 2000). The live working of $10 \mathrm{kV}$ cable to cut off and contact the lead wire is a method of operation to complete the power cable fault repaired in the uninterruptible power supply conditions (Wang Jianjun et al, 2014). But in live working process is often due to the distance is too large form cut off point and contact point of up-cable lead, down-cable lead, and the uplead, down-lead is long, when charged cut off and contact the cable lead, because lead cannot be effectively fixed (Hu Yi et al, 2014), the lead easily to touch a charged body, which occurred in personnel or equipment accidents, there is a big security risk. So it is need to develop a kind of instruments, can effectively fixed the lead, to reduce the risk of live working when cut off and contact the lead.

In this paper, the development of industrial equipment should meet the following requirements:

(1)Developed instruments can fixed a long lead effectively, prevent accidents caused by the lead to touch near the charged body.

(2)Developed instruments should be simple, easy to use, improve work efficiency in the premise of ensuring safety of operations.

(3)Developed instruments should have sufficient mechanical strength and insulating properties, comply with the relevant requirements of the State Grid Corporation Standard.

\section{STRUCTURE DESIGN OF INSULATING SUPPORTING FRAME}

According to the above requirements, this paper designed insulating support frame for $10 \mathrm{kV}$ cable charging cut off and contact the lead wire $(\mathrm{Pu}$ Lianggui et al, 2006) (Liu Hongwen, 2011). This insulating support frame includes an insulating cross arm and fixed to the cross arm of the lead fixture and shaft fixture (Hu Yi, 2003). Specific structure shown in figure 1 and figure 2.

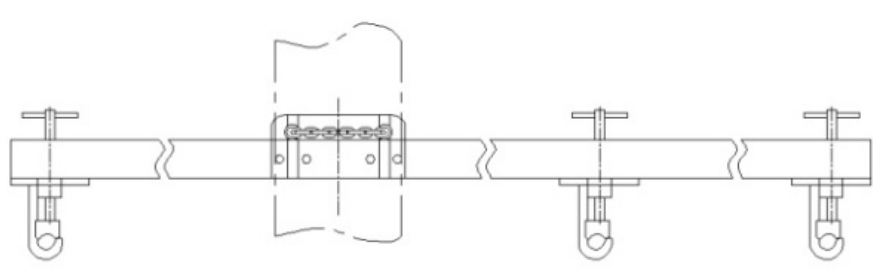

Figure 1. A schematic front view of the structure

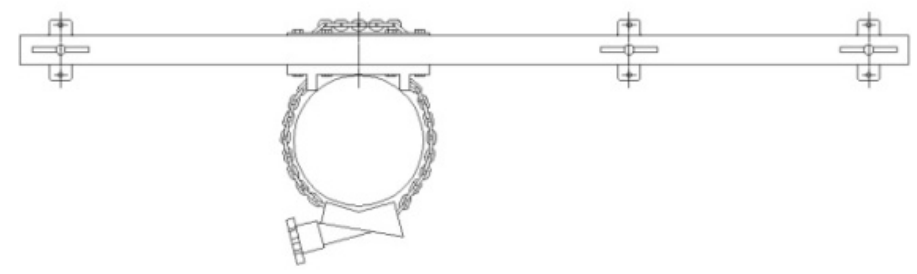

Figure 2. Overlooking view of the structure

As shown in figure 1, lead fixture includes a base, fixed chuck, activities slider, fastening screw, the base is fixed on the insulation cross arm, stationary chuck attached to the underside of the base, activities slider connected to the fixed chuck, stationary chuck 
includes connection plate and the board hook to connect to the side of the stationary chuck, board hook's outside is an arc-shaped collar, fastening screw through the insulating cross arm, a base, connected base plate is fixedly connected with the activities slider, upper end of the fastening screw there is a rocker, the thickness direction of the activities slider has a groove which is matching the board hook's width dimension, these two cooperated with gap of the recess, there is an arc-shaped groove on the tangent plane of activities slider and collar, there is a screw pit matched fastening screw on the connection baseboard. It has three sets lead fixtures, it is located the ends of the Insulating cross arm and with one end at a distance of three-tenths, it is used for fixing the cable's up lead and under lead.

As the figure 1 and figure 2 shows, shaft fixture consists of a chain, a shaft support base which is located in the midpoint of the length of insulating cross arm and a chain fixtre used for fixed the concrete pole shaft. Among them, shaft support base is an elongated whole thing forged of A4 aluminum, along its longitudinal there have symmetry for through-hole through which the chain.

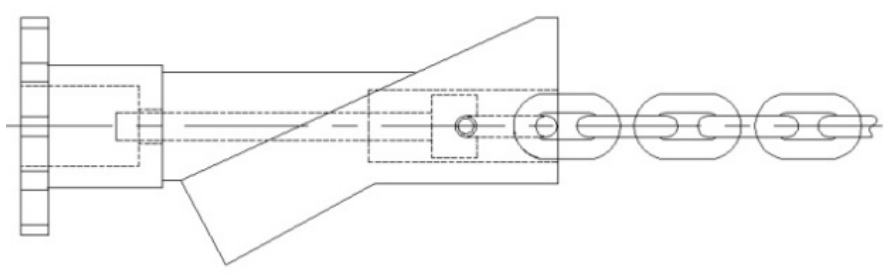

Figure 3. Main structure diagram of chain fixture

As shown in Figure 3, chain fixture includes a support base, adjustable handle. Adjustment handle located at one end of longitudinal of the support base, there is a shaft groove on the one side of the support base, along the longitudinal of the upper surface has a chain groove, it has a through hole within the entities which is outside of the chain groove, one end of the through hole is a square hole, the other end of the hole is a round hole. There is a screw in the through hole, one end of the screw has an outer diameter smaller than the square hole for connection to the chain connector, the length of the square hole is greater than the length of the connector, the other end of the screw through the adjustment handle, the threaded hole could match the screw at the inwall of the adjustment handle, it has a bayonet for fixing a chain on the end of the relative adjustment handle of the chain groove.

\section{STRENGTH CHECKS OF THE INSULATING SUPPORT FRAME}

The insulating support frame mainly subjected to bending moment when it worked for $10 \mathrm{kV}$ cable live working for cut off and contact the lead wire, therefore, this article is only calibrated the bending stress which is suffered by insulating support frame. Insulating support frame simplified mechanical model shown in figure 4 .

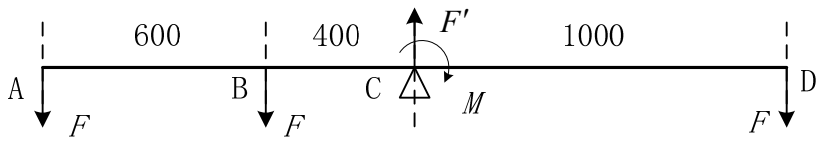

Figure 4. Insulating support frame simplified mechanical model

The cross arm of insulating support frame is made of 3640 epoxy phenolic glass hollow tube, bending strength $\sigma \mathrm{s}$ is $68.6 \mathrm{MPa}$, take a safety factor is 2.5 , then the material allowable bending stress $[\sigma \mathrm{s}]$ is,

$$
\left[\sigma_{s}\right]=\frac{\sigma_{s}}{n}=\frac{68.6 \mathrm{MPa}}{2.5}=27.44 \mathrm{MPa}
$$

where $\sigma=$ Bending strength; and $n=$ Safety factor, taking 2.5.

The external force $\mathrm{F}$ of insulating support frame in $\mathrm{A}, \mathrm{B}$ and $\mathrm{D}$ point is,

$$
F=w l g=2 \mathrm{~kg} / \mathrm{m} \times 5 \mathrm{~m} \times 9.8 \mathrm{~N} / \mathrm{kg}=98 \mathrm{~N}
$$

where $w=$ unit weight of insulation bypass wire; $l=$ the length of insulation bypass wire; $g=$ Acceleration of gravity.

By analysis of the insulating support frame's structure which can shows that the bending moment of maximum cross section at $\mathrm{C}$, It is also known that the sectional area of the entire place of insulating support frame cross arm, so C-section is the dangerous section, check on the bending stress of the cross section. The sectional area of insulating support frame cross arm shown in Figure 5.

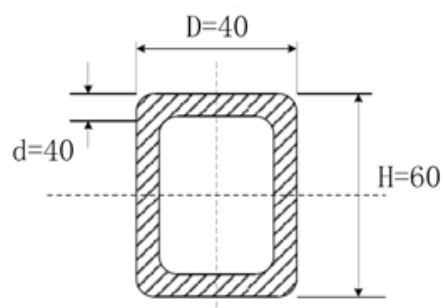

Figure 5. The sectional area of insulating support frame cross arm

The maximum bending moment Mmax in section C suffered is, 


$$
\begin{aligned}
M_{\text {max }} & =F \times\left(l_{\mathrm{AC}}+l_{\mathrm{BC}}\right)=196 \mathrm{~N} \times(1000 \mathrm{~mm}+400 \mathrm{~mm}) \\
& =274400 \mathrm{~N} \cdot \mathrm{mm}
\end{aligned}
$$

where, $l_{A C}=$ the distance between two points $\mathrm{A}$ and $\mathrm{C}$ of insulating support frame cross arm; $l_{B C}=$ the distance between two points $\mathrm{B}$ and $\mathrm{C}$ of insulating support frame cross arm.

Flexural section modulus in section $\mathrm{C}$ is,

$$
\begin{aligned}
W & =\frac{D H^{3}-(D-2 d)(H-2 d)^{3}}{6 H} \\
& =\frac{40 \mathrm{~mm} \times(60 \mathrm{~mm})^{3}-30 \mathrm{~mm} \times(50 \mathrm{~mm})^{3}}{6 \times 60 \mathrm{~mm}} \\
& =13583.3 \mathrm{~mm}^{3}
\end{aligned}
$$

where, $D=$ the section width of insulation brace cross arm, $H=$ the section height insulation brace cross arm, $d=$ the section thickness of insulation brace cross arm.

The bending stress of cross section $\mathrm{C}$ is,

$$
\sigma=\frac{M_{\max }}{W}=\frac{274400 \mathrm{~N} \cdot \mathrm{mm}}{13583.3 \mathrm{~mm}^{3}}=20.2 \mathrm{MPa}<27.44 \mathrm{MPa}
$$

Calculated by the above, the bending strength of insulation brace cross arm meet the requirements.

\section{TEST ITEMS AND RESULTS}

According to "State Grid Corporation of electrical safety work order" (line portion) standards, take power frequency withstand voltage test and static load test for insulation brace which in $10 \mathrm{kV}$ cable live working for cut off and contact the lead wire, experimental procedure shown in figure 6 , figure. 7 , the test results are shown in Table 1.

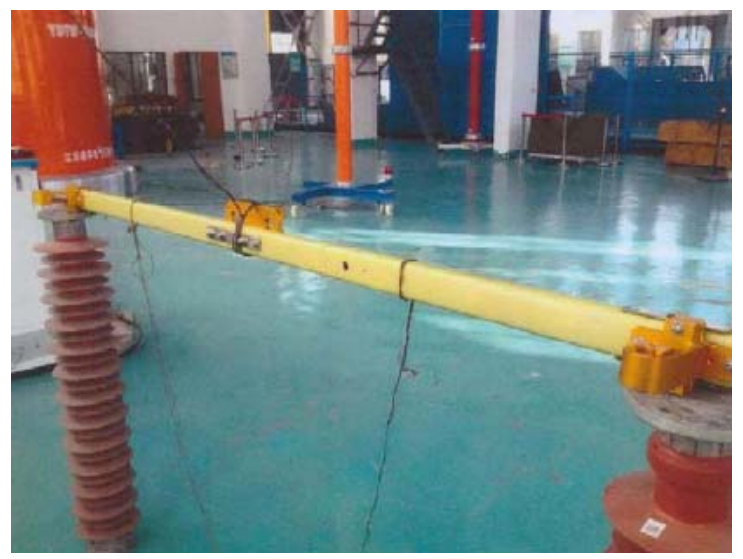

Figure. 6 The power frequency withstand voltage test process

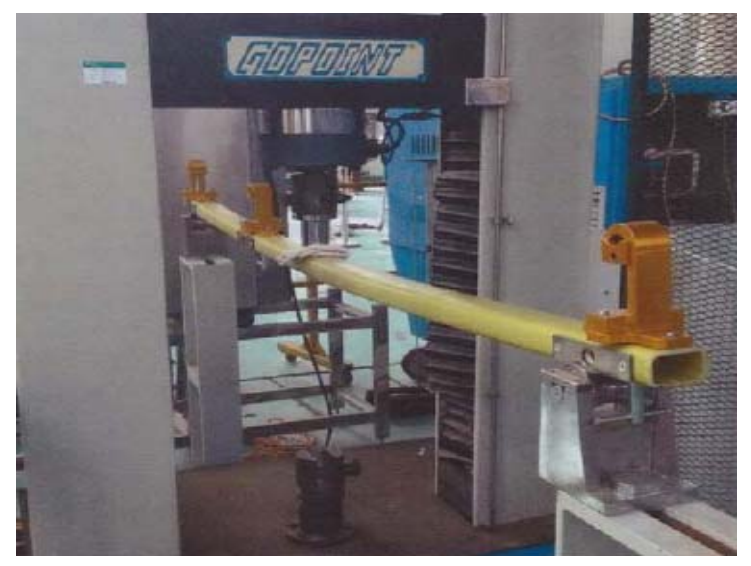

Figure. 7 Static load test process

Tab. 1 The test items and results of insulation brace

\begin{tabular}{ccccc}
\hline $\begin{array}{c}\text { The serial } \\
\text { number }\end{array}$ & The test items & $\begin{array}{c}\text { Standard } \\
\text { requirement }\end{array}$ & Test results & evaluation \\
\hline 1 & The power frequency & $0.4 \mathrm{~m}$, & $0.4 \mathrm{~m}, 101.2 \mathrm{kV} / 1 \mathrm{~min}$, no flashover, no \\
breakdown & $\begin{array}{c}\text { Meet the } \\
\text { requirements } \\
\text { withstand voltage test } \\
2\end{array}$ & Static load test & $929.04 \mathrm{~N}, 5 \mathrm{~min}$ & $1210 \mathrm{~N}, 5 \mathrm{~min}$, no visible damage and \\
deformation & requirements \\
\hline
\end{tabular}

The table 1 shows that the insulation brace test result is qualified, electric performance and mechanical performance conforms to the requirements.

\section{INSULATION BRACE USAGE AND OPERATION PROCESS}

The insulation brace is mainly used for connected the upper end of the lead to the line of $10 \mathrm{kv}$ distribution network which is in $10 \mathrm{kV}$ cable live working for cut off and contact the lead wire, when it is no intermediate fixtures, a long wire can bring larger security risks to the actual operation of assignment. The insulation brace actual usage as shown in figure
8.

When charged broken wire, first installation insulation brace cross arm to fixed wire, installation location determined according to the actual situation and when installation, shall ensure that the insulation brace cross arm and the concrete pole shaft connection is firm, second used insulation arm car, according to the SGC standardization process disconnect cable wire, finally to remove fixed lead, demolition wire at this time should ensure that timely fixed inside the snap ring of insulation cross arm chuck and swing does not occur. 


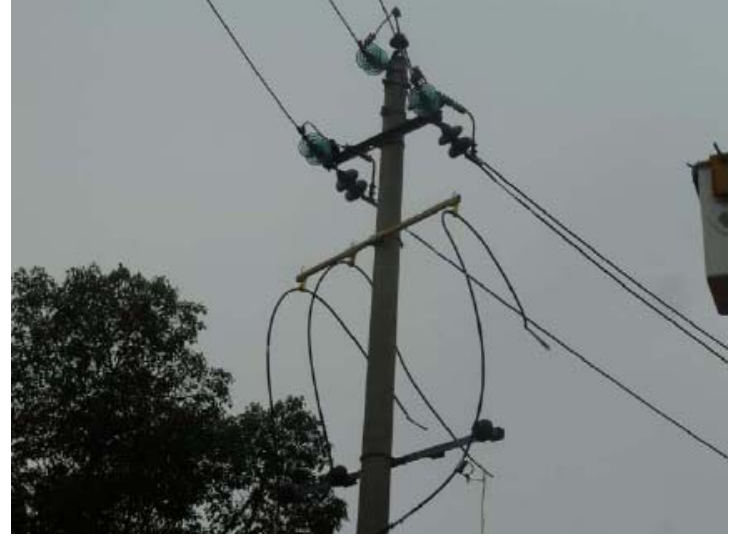

Figure 8 . The insulation brace actual usage

When charged lead operations, the first step to install the insulation cross arm to fixed lead, operating methods is the same with the live working for cut off the lead's, second, the worker will be fixed the lead wire into card ring of the Insulating cross arm's chuck, to ensure that the lead phase sequence corresponds to the line, finally, workers turn to be removed lead wire from the insulating cross arm, according to standard operating procedures, then the workers can contact the lead by live working.

\section{CONCLUSION}

In this paper, the problems existing in the process of the live working of $10 \mathrm{kV}$ cable to cut off and contact the lead wire, to design an insulating support frame which can effectively reduce the security risk of such job. By the above analysis, the following conclusions can be obtained.

(1)This article is designed insulating support frame mechanical properties and electrical properties can meet the "live working and industrial equipment" and "electrical safety work order (line portion)" requirements.

(2)This article is designed insulating support frame can effectively fixed the up lead and the under lead of the cable, effectively prevent the lead swing, avoiding the personnel or equipment accidents caused by the swing lead touch the charged body nearby.

(3)This article is designed insulating support frame has simple structure, and easy to use, can effectively improve work efficiency of the live working of $10 \mathrm{kV}$ cable to cut off and contact the lead wire, it has broad prospects for use.

\section{REFERENCES}

GB/T 18857-2008 Technical guide for live working in distribution line, 2008.

$\mathrm{Hu}$ Yi. 2003. Compilation Introduction of National Standard GB/T18857-2002. Technical specification of distribution lines live working. .Electric Power Standardization \& Measurement,46(4): 8-11.

$\mathrm{Hu}$ Yi, Liu Kai, Peng Yong, et all. 2014. Research Status and Development Trend of Live Working Key Technology.High Voltage Engineering, 40(7): 1921-1931.

$\mathrm{Hu}$ Yi, Wang Lining, Liu Songxi, et all. 2000. Live-working Method and Safety Protection for Distri bution Line.High Voltage Engineering, 26(5): 34-35.

Liu Hongwen. 2011. Mechanics of Materials. Bei Jing: Higher Education Press.

Pu Lianggui, Ji Minggang. 2006. Machine Design. Bei Jing: Higher Education Press.

Q/GDW 1799.2-2013 State Grid Corporation of China Working Regulation of Power Safty Transmission Line Section, 2013.

Wang Jianjun, Wu Jihao, Su Ziming. 2014. Simulation and Experimental Reasearch on Live Working Technology for 10 kV Cable Terminal. Electric Power Construction, 35(2): 4146. 